\title{
GOVERNANÇA NO ÂMBITO DA ÁREA DA TECNOLOGIA DE INFORMAÇÃO: PERCEPÇÃO DOS SERVIDORES DA UNIVERSIDADE FEDERAL DO PAMPA - UNIPAMPA
}

\author{
Nome \\ Patricia Picolotto \\ Instituição/Afiliação \\ Universidade Federal de Santa Maria \\ País \\ Resumo da \\ Brasil \\ Biografia \\ Mestranda em Gestão de Organizações Públicas pela Universidade Federal de \\ Santa Maria (UFSM). \\ Nome \\ Elizeu da Silva Costa Junior \\ Instituição/Afiliação \\ Universidade Federal de Santa Maria \\ País \\ Brasil \\ Resumo da \\ Biografia \\ Mestrando em Gestão de Organizações Públicas pela Universidade Federal de \\ Santa Maria (UFSM) \\ Nome \\ Renan Kaizer dos S. Roscoff \\ Instituição/Afiliação \\ Universidade Federal de Santa Maria \\ País \\ Brasil \\ Resumo da \\ Biografia \\ Mestrando em Gestão de Organizações Públicas pela Universidade Federal de \\ Santa Maria (UFSM) \\ Nome \\ Nelson Guilherme Machado Pinto \\ URL \\ http://buscatextual.cnpq.br/buscatextual/visualizacv.do?id=S6344501 \\ Instituição/Afiliação \\ País \\ Universidade Federal de Santa Maria \\ Resumo da \\ Brasil \\ Biografia \\ Professor Adjunto do Departamento de Administração UFSM, professor do \\ Programa de Pós-Graduação em Organizações Públicas da UFSM e Doutor em \\ Administração pela UFSM. E-mail: nelguimachado@hotmail.com
}

\section{RESUMO}

O objetivo deste estudo é avaliar se na Universidade Federal do Pampa - UNIPAMPA - as práticas voltadas à governança estratégia no âmbito da área Tecnologia da Informação e Comunicação (TIC), atinge os objetivos institucionais propostos no Plano de Desenvolvimento Institucional (PDI) 2014-2018, segundo a percepção dos servidores da área. Os gestores - seja em funções de TIC ou não - devem colaborar e trabalhar em conjunto a fim de garantir que a TIC esteja inclusa na abordagem de governança e gestão. Esta pesquisa é caracterizada como quantitativa, descritiva, fundamentada no levantamento de dados primários, através de um questionário, utilizado como instrumento de coleta de dados, enviado via e-mail, por intermédio de um estudo de caso na Universidade Federal do Pampa. Os principais resultados e contribuições do estudo são que a área de TI na universidade estudada possui alinhamento com os objetivos institucionais, contudo, a governança de TI não está clara ou carece de alinhamento organizacional, bem como, falta controle e monitoria do desempenho da área de TI, pela alta administração.

Palavras-chave: Tecnologia da Informação, Governança, Gestão Pública, Ensino Superior, TIC. 


\section{INTRODUÇÃO}

As organizações possuem grande dependência dos recursos da tecnologia da informação, exigindo-se métodos e procedimentos que resulte na entrega qualitativa de produtos e serviços aos seus clientes e usuários. A entrega dos serviços de TI com qualidade, representa um meio de melhorar o desempenho da organização (REZENDE, 2002). A partir da adequada gestão de serviços em TI, é possível avaliar se as necessidades organizacionais estão sendo atendidas, destacando-se, neste contexto, a alocação de recursos de maneira eficaz e eficiente (MAGALHÃES; PINHEIRO, 2007).

A área da tecnologia da informação, no governo, apresenta-se como E-GOV e cada vez mais ganha força no setor público, à medida que se utiliza de instrumentos que visam a eficiência, a prestação de contas e ainda a inovação. O segmento de tecnologia da informação, no setor público, caracteriza-se como o elemento-chave para as possíveis reformas propostas pelos gestores públicos, evidenciado pelo fato dos cidadãos exigirem que os serviços prestados sejam similares ao setor privado (HUGHES, 2003).

O código de ética do servidor público traz que, deve-se tratar cuidadosamente os usuários dos serviços, aperfeiçoando o processo de comunicação e o contato com o público, sendo notório a busca pela qualidade dos serviços púbicos. Na Administração Pública Federal o planejamento das ações da área de Tecnologia da Informação, deve estar alinhado com as ações do Plano de Desenvolvimento Institucional (PDI) e demais estratégias do Governo Federal. Conforme o Decreto n. ${ }^{\circ}$ 5773/2006, o PDI é o documento de planejamento estratégico que reúne objetivos e metas propostos Instituição Federal de Ensino Superior (IFES) (BRASIL, 2006). As IFES subordinam-se, ainda, a Lei Federal n 10.861/2004, com o objetivo de assegurar a melhoria e a qualidade na educação superior (BRASIL, 2004).

A Universidade Federal do Pampa - UNIPAMPA, é uma instituição de ensino superior pública federal brasileira, autarquia vinculada ao Ministério da Educação, portanto regida por normas e princípios atinentes e sob fiscalização dos órgãos de controle externo como o Tribunal de Contas da União - TCU. No que se refere ao planejamento estratégico para a Administração Pública Federal o TCU em seu acórdão n. ${ }^{\circ} 003.732$ (2014) traz que "Cabe também à alta administração estabelecer os níveis de riscos aceitáveis para subsidiar o processo de tomada de decisão, sobretudo as de nível estratégico" (BRASIL, 2014). Nesta linha a área de TI passou a ser estratégica para as organizações gerando valor e como um diferencial competitivo (REZENDE, 2002). 
O planejamento estratégico de TI exige uma coordenação com as unidades de negócios da organização priorizando os planos com maior probabilidade de alcançar os benefícios desejados e a fim de alocar os recursos de maneira efetiva (ISACA,2012). O planejamento estratégico da área de TI na Universidade Federal do Pampa - UNIPAMPA, é representado pelo Conselho Gestor de TIC - CGTIC, órgão máximo da Diretoria de Tecnologia da Informação e Comunicação, com competências normativas, deliberativas e consultivas sobre a Política Geral de Tecnologia da Informação e Comunicação na Universidade. Entre as suas competências, de acordo com o artigo 10, da Resolução ${ }^{\circ}$ 19/2010, é o "de estabelecer, em consonância com as normas superiores da Universidade, diretrizes gerais de temas na área de Tecnologia da Informação e Comunicação da Universidade".

De acordo com o Plano Diretor de Tecnologia da Informação e Comunicação PDTIC UNIPAMPA (2016), o Conselho Gestor de TIC é composto pelo grupo do Conselho propriamente dito e apoiado técnica e administrativamente pelos Grupos Assessores (GAs), que são propostos e compostos, sob demanda, a critério do Conselho. Conforme o Referencial Básico de Governança do Tribunal de Contas da União (2014), a alta administração é responsável por viabilizar e garantir o adequado funcionamento da gestão de riscos, com o estabelecimento de diretrizes, a criação de estruturas, se necessário, e a definição de papéis e responsabilidades.

Com a crescente importância estratégica da área de Tecnologia da Informação - TI, devido a movimentação massiva e o armazenamento de dados da Administração Pública Federal, o Tribunal de Contas da União conta com a Secretaria de Fiscalização de Tecnologia da Informação - SEFTI, uma unidade especializada na área. Dentre as suas atribuições, além da realização de fiscalizações da governança de TI, nos sistemas informatizados da Administração Pública, produz manuais, notas técnicas e procedimentos para a área de TI.

A Nota Técnica - SEFTI/TCU (2014), estabelece que questões importantes relacionadas à alocação de recursos, à realização de investimentos e à priorização de projetos de TI são tipicamente decididas por estruturas organizacionais. Por consequência, como a alta administração, o comitê de TI torna-se um setor estratégico no cumprimento dos objetivos fim da instituição, isto é, ensino, pesquisa e extensão.

Assim, diante desse contexto, o objetivo deste estudo é avaliar se na Universidade Federal do Pampa - UNIPAMPA - as práticas voltadas à governança estratégia no âmbito da área Tecnologia da Informação e Comunicação (TIC), atinge os objetivos institucionais 
propostos no Plano de Desenvolvimento Institucional (PDI) 2014-2018, segundo a percepção dos servidores da área.

O artigo está organizado em cinco seções, sendo a introdução a primeira delas, a segunda traz o referencial teórico, referindo sobre governança e governança de TI, a terceira relata-se a metodologia de pesquisa e, na quarta seção, os resultados e discussões. Por fim, apresenta-se as considerações finais do estudo.

\section{REFERENCIAL TEÓRICO}

\section{1 GOVERNANÇA}

A governança compreende a estrutura (administrativa, política, econômica, social, ambiental, legal e outras) posta em prática para garantir que os resultados pretendidos pelas partes interessadas sejam definidos e alcançados (IFAC, 2013). Já governança pública pode ser entendida como o sistema que define o equilíbrio de poder entre os envolvidos - cidadãos, representantes eleitos, alta administração, gestores e colaboradores - com perspectivas a permitir que o bem comum perdure sobre os interesses de pessoas ou grupos (MATIASPEREIRA, 2010).

De acordo com Matias-Pereira (2010, p. 109) o conceito de governança, em um primeiro momento, ficou "restrito à noção de desempenho gerencial e administrativo - tendo sua origem em estudos e relatórios de agências multilaterais, em especial do Banco Mundial, no início da década de 1990". Com o tempo, esse conceito foi se difundindo e adquirindo importância, sendo hoje, bastante amplo, mas conforme afirma Alves (2001), é frequentemente difuso, podendo ser aplicado tanto a métodos de gestão da empresa (governança corporativa) quanto a meios de preservação do meio ambiente (governança ambiental) ou formas de combate ao suborno e à corrupção de funcionários públicos (governança pública). Não obstante seu caráter difuso, o conceito de governança tem como ponto de partida a busca do aperfeiçoamento do comportamento das pessoas e das instituições (ALVES, 2002).

Mesmo que a governança estivesse interligada com questões de governo, foi nas empresas de capital, no setor privado, que ela se desenvolveu primeiramente (MATIASPEREIRA, 2010). Assim, Marques (2007, p. 10), descreve de forma sucinta que governança corporativa são "os mecanismos ou princípios que governam o processo decisório dentro de uma empresa". O significado de governança corporativa para a estabilidade e equidade da 
sociedade é que a governança corporativa se preocupa em manter o equilíbrio entre metas sociais e econômicas e entre metas individuais e coletivas (CADBURY, 2000).

O Instituto Brasileiro de Governança Corporativa (2015) afirma que as boas execuções de Governança Corporativa convertem convicções em orientações firmes, alinhando interesses com o intuito de melhorar a organização, simplificando seu acesso a recursos e contribuindo para sua longevidade. Complementa Marques (2007, p. 10) que "a governança corporativa agrega valor, apesar de, isoladamente, não ser capaz de criá-lo", portanto, ela não contribui na autonomia da organização, mas ajuda a equilibrar a qualidade do negócio, o lucro e a boa administração através da gestão transparente e responsável.

Para manter boas práticas e de forma padronizada, a governança corporativa deve apoiar-se em princípios, como o de transparência, equidade e prestação de contas, tendo como características principais a definição clara dos papéis e responsabilidades dos seus gestores na formulação, aprovação e execução das políticas e diretrizes referentes à condução dos negócios. Assim, é fundamental o equilíbrio entre as questões econômicas, financeiras, ambientais e sociais do empreendimento, na busca de aperfeiçoar e estreitar as relações com acionistas, clientes, colaboradores, sociedade e demais stakeholders (partes interessadas) (MATIAS-PEREIRA, 2010).

O Estado Democrático de Direito exigiu uma administração pública direcionado para a eficiência, cuja implementação ocorreu através de reformas administrativas. Foi, inicialmente, necessária uma nova reforma administrativa e de Estado, conceituada como governança, que tem como instrumento a ação conjunta, de maneira eficaz, transparente e compartilhada, pelo Estado, pelas empresas e pela sociedade civil, buscando um meio inovador para solucionar problemas sociais e estabelecendo perspectivas e oportunidades de um progresso sustentável para todos (LÖFFER, 2001).

Quanto a governança pública, a mesma está associada a uma mudança na gestão política. Trata-se de uma tendência de explorar a autogestão nos campos social, econômico e político (JANN, 2003) epode ser observada por quatro aspectos: (a) sociedade e Estado, que determina diretrizes orientadoras para a atuação dos agentes públicos e privados regulamentados pela Constituição e concebe possibilidades estruturais de administração e controle do Estado; (b) entes federativos, esferas de poder e políticas públicas, que atenta com as políticas públicas e as conexões estruturais, incluindo esferas discrepantes, poderes, níveis de governo e representantes da sociedade civil organizada; (c) órgãos e entidades, que garantem o cumprimento da norma; e (d) atividades intraorganizacionais, que reduz os riscos, melhora os resultados e agrupa valor aos órgãos ou entidades (TCU, 2014). 
Figura 1: Perspectivas de observação da governança no setor público

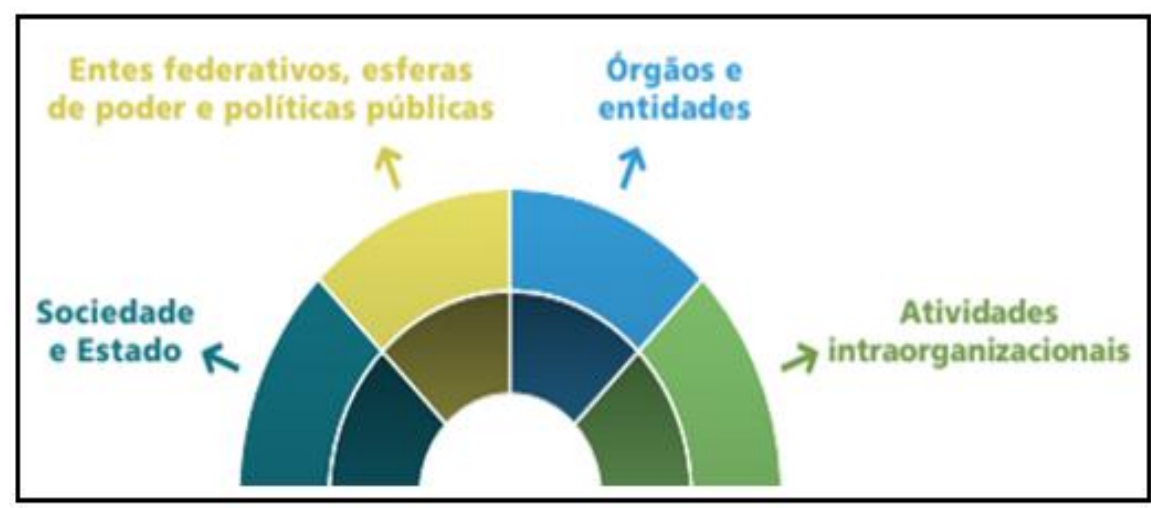

Fonte: TCU, 2014.

Assim, a governança no setor público compreende, essencialmente, os mecanismos de liderança, estratégia e controle postos em prática para avaliar, direcionar e monitorar a atuação da gestão, com vistas à condução de políticas públicas e à prestação de serviços de interesse da sociedade (TCU, 2014). Ocorre que atualmente, o governo tem buscado o alinhamento sobre os diversos conceitos de governança, seja pública, corporativa, de TI, entre outras, a fim de apoiar os entes governamentais na tarefa de dirigir corretamente os recursos aplicados. Com isso, necessário se faz um melhor entendimento sobre o tema de governança de TI, que será exposto a seguir, considerada uma das mais recentes formas de governança aplicável.

\subsection{GOVERNANÇA DE TI}

A governança de TI compreende o conjunto de mecanismos para assegurar que o uso da TI agregue valor ao negócio das organizações, com riscos aceitáveis. São estruturas organizacionais, processos, controles e outros componentes que objetivam evitar ou mitigar deficiências ainda comuns na gestão de uma organização, como falta de capacitação de pessoal, inadequação do processo de planejamento, recorrência de projetos malsucedidos e contratações que não atendem às necessidades do negócio (TCU, 2014).

O sistema de governança de TI compreende o conjunto de estruturas, de processos, de pessoas, entre outros componentes viabilizadores da governança de TI, que interagem com objetivo de entregar benefícios para a organização com recursos otimizados e riscos gerenciados (TCU, 2014). Governança é definida como a especificação do framework dos 
direitos decisórios e das responsabilidades para estimular comportamentos desejáveis e, em última instância, em quão bem a firma atinge as metas de desempenho desejadas (PETER, 2006).

A tecnologia da informação se torna cada vez mais presente no mundo corporativo tornando-se uma ferramenta fundamental na tomada de decisões. As organizações e seus executivos se esforçam para manter dados de alta qualidade a fim de contribuir com as decisões corporativas, buscar excelência operacional por meios confiáveis e eficientes, assim, buscam minimizar os riscos relacionados à informação e maximizar valores. Idealizada pela ISACA (Information Systems Audit and Control Association), a obra COBIT 5 (Control Objectives for Information and Related Technologies), ajusta-se como recurso educacional para profissionais de segurança, abordando risco, garantia e governança de TI (ISACA, 2012).

Assim, o manual, COBIT 5, informa que governança de TI compreende todas as práticas relacionadas a avaliar, direcionar e monitorar os processos e atividades de TI. Este direciona como são discutidos e aprovados os direitos de decisão, as políticas e normas de alinhamento estratégico, a implementação de processos e os mecanismos de controle que direcionarão a gestão da TI. O ciclo de implementação proposto, retrata uma forma das organizações usarem o COBIT 5 para lidar com a complexidade e os desafios normalmente encontrados durante as implementações (ISACA, 2012).

Figura 2 - Ciclo de vida da implantação do COBIT 5

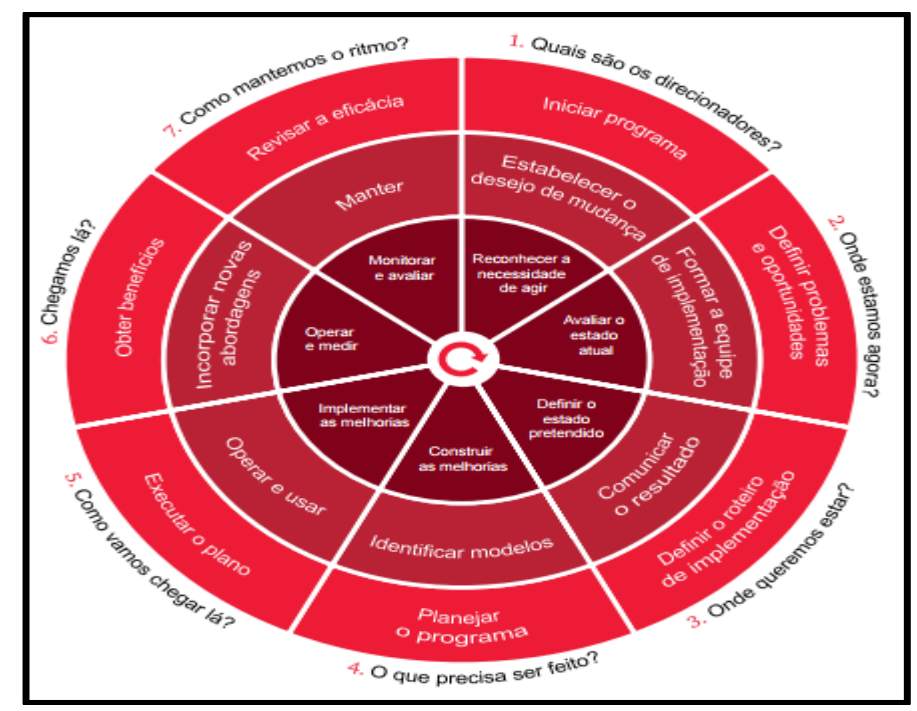

Fonte: ISACA, 2012. 
A governança em TI alinha as necessidades organizacionais com as partes interessadas, priorizando os objetivos, definindo a direção, monitorando o desempenho e a conformidades bem como o alcance dos objetivos estratégicos previamente estabelecidos (ISACA,2012). Conforme, IT Governance Institute (ITGI) a alta administração possui a responsabilidade sobre a governança de TI, a fim de garantir que a mesma sustente a atenda as estratégias e os objetivos do negócio.

É notório, o avanço da quantidade e da qualidade das informações disponibilizadas nas instituições de ensino, principalmente aquelas destinadas aos alunos, professores e demais profissionais envolvidos no processo educacional (MORAN, 2007). Reconhecer as suas funcionalidades e aplicabilidades, no cotidiano acadêmico, é de fundamental importância a fim de atender os objetivos institucionais e melhorar os serviços prestados a comunidade (CERNY, 2009).A Tecnologia da informação caracteriza-se pela utilização de ferramentas que facilitam e objetivam o alcance dos objetivos comuns (MORAN, 2012). Entende-se, ainda, a área da TI como aquela que se utiliza de meios tecnológicos para produzir, transmitir, disseminar além de usar diversas informações geradas (VIEIRA, 2011).

As instituições de ensino tendem a ajustarem-se a nova perspectiva de um mundo globalizado e assim, buscam atender as demandas inerentes ao ensino, pesquisa e extensão, alinhadas aos anseios de uma sociedade cada vez mais ávida por informação (MELO ; COLOSSI, 2004). O trabalho do professor, tende a ser desafiador no processo de ensino e aprendizagem pois, é peça fundamental na inclusão digital, nas demandas diárias, aprimorando-se, e aprendendo a lidar com o diferente, incluindo novas tecnologias no processo educacional (MORAN, 2012).

O planejamento estratégico da Universidade Federal do Pampa - UNIPAMPA - traz como arcabouço a tecnologia da informação, presente no Plano de Desenvolvimento Institucional (PDI) 2014-2018, especificado no objetivo 6 - ofertar serviços e soluções da Tecnologia da Informação e Comunicação para a comunidade universitária. Conforme o Referencial Básico de Governança do Tribunal de Contas da União (2014), e a norma ABNT NBR ISO/IEC 38500, que trata da Governança Corporativa de Tecnologia da Informação, dispõe que faz-se necessário que os dirigentes avaliem os desenvolvimentos em TI e os processos para garantir a TI nas necessidades futuras do negócio. Quanto a avaliação da governança em TI, seu desempenho consiste na eficácia com que os arranjos de governança estimulam comportamentos desejáveis e, em última instância, em quão bem a firma atinge as suas metas de desempenho desejadas (PETER, 2006). 
A boa governança melhora a tomada de decisão e o desempenho em TI, permite que as pessoas certas tomem as decisões certas e monitorem o seu desempenho (PETER, 2006). No mesmo sentido, Chan e Reich (2007) acreditam que o alinhamento estratégico do negócio com TI tende a alavancar a organização e por consequência, obter alto desempenho e custobenefício, assim entendem que tal alinhamento é de cunho estratégico e fundamental ao sucesso e desempenho da organização.

\subsection{PLANEJAMENTO ESTRATÉGICO NO SETOR PÚBLICO}

Segundo Drucker (1991), Planejamento Estratégico pode ser definido com um processo contínuo, sistemático, organizado e capaz de "prever o futuro", de maneira a tomar decisões que minimizem riscos para as organizações. Nesse contexto, Bryson e Roering (1987) conceituam o planejamento estratégico como sendo um esforço disciplinado para tomar decisões e definir ações fundamentais que moldam e orientam o que uma organização é, o que faz e por que faz. Conforme Pfeiffer (2000), o planejamento estratégico é realizado por diversos tipos de organização: empresas privadas, ou parte delas; organizações não governamentais; administração pública, ou parte dela; ou, ainda, um município.

Dessa forma, pode-se conjecturar que os anseios de um futuro promissor na administração de órgãos públicos passam pela realização de maiores esforços na elaboração de seus planejamentos estratégicos, isso porque esta prática de gestão tem trazido inúmeros benefícios para seus gestores e para a sociedade como um todo (BRYSON e ROERING, 2010).

Embora as instituições federais também utilizem ferramentas estratégicas de gestão, o ambiente organizacional do setor público possui características diferentes do setor privado, como a complexidade devido a um grande número de partes interessadas, impondo restrições e exigências aos gestores. Também pode-se citar o fato das organizações públicas serem "sistemas abertos", facilmente influenciáveis por acontecimentos externos, com ausência de pressões competitivas, uma vez que os órgãos públicos possuem poucos rivais para prestação de seus serviços, além da instabilidade gerada por questões políticas, impondo, algumas vezes, horizontes temporais de curta duração sobre os gestores públicos (BOYNE, 2002).

De acordo com Mizael et. al. (2013), as Instituições Federais de Ensino Superior (IFES) têm usado como ferramenta o Plano de Desenvolvimento Institucional (PDI), que é um documento norteador de planejamento legalmente instituído. A Universidade Federal do Pampa - UNIPAMPA, enquanto objeto de estudo, utiliza-se deste documento. 
O PDI tem suas raízes em duas atribuições definidas pela Lei de Diretrizes e Bases da Educação (1996), figurando de modo determinante com o Decreto 3.860 de 9 de julho de 2001 (SEGENREICH, 2005). Entretanto, somente em 2006, através do Decreto $\mathrm{n}^{\circ} 5.773$ de 9 de maio, foi disposto sobre o formato de apresentação do PDI, além de estruturar as funções de avaliação do ensino superior (BRASIL, 2006).

O Plano de Desenvolvimento Institucional (PDI) é uma ferramenta de planejamento estratégico que sintetiza as metas e os métodos propostos pela instituição durante um período de 5 anos, contando com a participação de toda a comunidade acadêmica. Ele serve como documento norteador para diversas etapas da gestão de uma Instituição Federal de Ensino Superior, definindo sua filosofia de trabalho, a missão a que se propõe, as diretrizes pedagógicas que orientam suas ações, a estrutura organizacional e as atividades acadêmicas que desenvolve e pretende desenvolver (MEC, 2007).

Na visão de Schmitt e Mafra (2003), o PDI possui também como finalidade tornar-se uma ferramenta de avaliação das Instituições de Ensino Superior, quando do credenciamento, autorização e reconhecimento de seus cursos. Neste sentido, ele configura-se como o principal documento no qual se baseia a avaliação realizada pelos órgãos oficiais do Estado.

Dessa forma, o PDI deve descrever, em forma de planejamento estratégico, todos os objetivos que se pretende alcançar e de que maneira o trabalho deve ser conduzido para atingi-los. Outro ponto importante é a transparência que deve existir na sua elaboração e apresentação, além da clareza e objetividade do texto, expressando viabilidade para o seu cumprimento integral (PDI, 2014).

Uma gestão responsável dos processos acadêmicos e administrativos nas Instituições de Ensino Superior (IES) compreende atitudes e procedimentos de seus administradores que vão além de ações de extensão, envolvendo planejamento, monitoramento e avaliação de resultados no sentido de atingir metas e objetivos estabelecidos em seu PDI (COLOMBO, 2011). De acordo com Muriel (2006), ao tornar o PDI obrigatório para o credenciamento de novas IES e a autorização de novos cursos, o governo demonstrou certa preocupação com uma gestão responsável ou o crescimento de uma instituição já existente. Assim, apesar de ser obrigatório por força de lei, é uma oportunidade para as IES realizarem um planejamento que de fato traga resultados positivos.

Na UNIPAMPA, a participação da comunidade é exercida através de três etapas: virtual, presencial e seminário de revisão. A primeira etapa, de maneira virtual, foi proposta pela instituição a fim de minimizar as barreiras geográficas e permitir o registro de todas as contribuições de forma mais rápida, coletiva e participativa. Esta participação acontece 
através de enquetes publicadas via moodle onde é possível contribuir pontualmente na construção do documento ou levantar alguma problemática. Na segunda etapa, de forma presencial, são debatidas as questões levantadas na etapa virtual, com a participação da equipe de elaboração e da gestão da Universidade. Em seguida, na terceira etapa, após a inclusão das metas e objetivos propostos pela comunidade acadêmica nos encontros presenciais, haverá o Seminário de Revisão, onde, mais uma vez, acontece um debate através de uma comissão com representantes de todas as unidades (PDI, 2014).

\section{PROCEDIMENTOS METODOLÓGICOS}

A pesquisa é se centra na objetividade, só podendo ser realizada através da análise de dados brutos, retirados com o auxílio de um instrumento padronizado e neutro (FONSECA, 2002). Ainda, busca resultados exatos evidenciados por meio de variáveis preestabelecidas, em que se verifica e explica a influência sobre as variáveis, mediante análise da frequência de incidências e correlações estatísticas (MICHEL, 2005).

O levantamento de dados se através de dados primários, com aplicação de um questionário como instrumento de coleta de dados (Anexo I), via e-mail, direcionado às pessoas cujo comportamento pretende-se conhecer (HAIR JUNIOR et al., 2005) e, com posterior análise através do Statistical Package for the Social Sciences - SPSS, um software do tipo científico. A população alvo foi composta por 45 (quarenta e cinco) servidores dos quais obteve-se 21 (vinte e um) respondentes do setor de tecnologia da informação da UNIPAMPA relativos aos serviços prestados e a sua percepção quanto a aderência a Nota Técnica 7/2014 (TCU).

Por se tratar de um setor estratégico na instituição, o questionário foi adaptado em conformidade a Nota Técnica 7/2014 (TCU), um manual de procedimentos norteadores para a gestão pública, na área de tecnologia da informação, em consonância com as práticas mais modernas na área de TI (COBIT). Nas variáveis do instrumento foi utilizada a escala Likert de 5 (cinco) pontos tendo como alternativas de resposta: 1 discordo totalmente, 2 discordo parcialmente, 3 indiferente, 4 concordo parcialmente e 5 concordo totalmente, sendo que a pontuação 5 (cinco) significa maior concordância por parte do respondente (MALHOTRA, 2012). 


\section{RESULTADOS E DISCUSSÕES}

O processamento, para posterior análise dos dados, foi realizado no software SPSS 20.0, o qual nos permite realizar a análise descritiva de dados. Analisando o perfil dos respondentes (Tabela 1) foi demonstrado que a maioria possui até 19 anos (42,9\%), sendo 76,2\% com formação de pós-graduação Latu Sensu, com tempo na instituição de 4 a 8 anos (80\%), sendo que 57,1\% dos respondentes possuem um tempo na função de 3 a 6 anos e função gratificada $(71,4 \%)$.

Tabela 1 - Perfil dos respondentes e análise descritiva e de frequência

\begin{tabular}{|c|c|c|c|}
\hline Variáveis & Alternativas & Frequência & Percentual válido** \\
\hline \multirow{3}{*}{ Idade* } & Até 19 anos & 9 & 42,9 \\
\hline & Dos 20 a 33 anos & 7 & 33,3 \\
\hline & Dos 34 a 41 anos & 4 & 19 \\
\hline \multirow{4}{*}{ Escolaridade* } & Ensino Médio & 1 & 4,8 \\
\hline & Ensino Superior & 1 & 4,8 \\
\hline & Pós-Graduação Latu Sensu & 16 & 76,2 \\
\hline & Pós-Graduação Strictu Sensu & 3 & 14,3 \\
\hline \multirow{2}{*}{ Função Gratificada } & Sim & 15 & 71,4 \\
\hline & Não & 6 & 28,6 \\
\hline \multirow{3}{*}{ Tempo de UNIPAMPA* } & Até 3 anos & 3 & 15 \\
\hline & De 4 a 8 anos & 16 & 80 \\
\hline & Acima de 9 anos & 1 & 5 \\
\hline \multirow{2}{*}{ Tempo de Função* } & De 3 a 6 anos & 12 & 57,1 \\
\hline & De 7 a 10 anos & 9 & 42,9 \\
\hline
\end{tabular}

*As variáveis idade, escolaridade, tempo de UNIPAMPA e tempo de função foram recodificadas, e divididas em classes, a partir dos quartis identificados

Fonte: Elaborada pelos autores (2017)

Quanto ao questionamento se existe uma política de governança de TI na UNIPAMPA, formalmente instituída, e que contemple princípios, diretrizes, dirigindo e monitorando a gestão e o uso da TI, 57\% dos respondentes discordam totalmente (Tabela 2). Neste demonstra-se adversidade quanto a necessidade de alinhamento às necessidades organizacionais, priorizando os objetivos, definindo a direção, monitorando o desempenho estratégico organizacional (ISACA,20012). Ainda, a pesquisa apontou que 88,9\% concordam que as pessoas influentes na instituição determinam a priorização de projetos de TI com base em critérios eminentemente políticos. 
Tabela 2 - Variáveis Relativas à Percepção dos Servidores - DTIC - UNIPAMPA

\begin{tabular}{|c|c|c|c|c|c|c|}
\hline VARIÁVEIS & & $\begin{array}{l}\text { Discordo } \\
\text { Totalmente }\end{array}$ & Discordo & Indiferente & Concordo & $\begin{array}{l}\text { Concordo } \\
\text { Totalmente }\end{array}$ \\
\hline \multirow{2}{*}{$\begin{array}{l}\text { Q6 - Existe uma política de governança de TI } \\
\text { formalmente instituída pela alta administração e que } \\
\text { contempla princípios e diretrizes além de dirigir e } \\
\text { monitorar a gestão e o uso da TI. }\end{array}$} & Frequência & 12,0 & 2,0 & 4,0 & 3,0 & 0,0 \\
\hline & Percentual & 57,1 & 9,5 & 19,0 & 14,3 & 0,0 \\
\hline \multirow{2}{*}{ Q7 - A DTIC gerencia os riscos existentes. } & Frequência & 2,0 & 6,0 & 3,0 & 9,0 & 1,0 \\
\hline & Percentual & 9,5 & 28,6 & 14,3 & 42,9 & 4,8 \\
\hline \multirow{2}{*}{$\begin{array}{l}\text { Q8 - A DTIC monitora o desempenho valendo-se de } \\
\text { processos e sistemas de mensuração apropriados. }\end{array}$} & Frequência & 3,0 & 3,0 & 8,0 & 6,0 & 1,0 \\
\hline & Percentual & 14,3 & 14,3 & 38,1 & 28,6 & 4,8 \\
\hline \multirow{2}{*}{$\begin{array}{l}\text { Q9 - A Governança em TI na instituição é conhecida e } \\
\text { publicizada. }\end{array}$} & Frequência & 8,0 & 5,0 & 6,0 & 1,0 & 1,0 \\
\hline & Percentual & 38,1 & 23,8 & 28,6 & 4,8 & 4,8 \\
\hline \multirow{2}{*}{$\begin{array}{l}\text { Q10 - A DTIC possui indicadores de desempenho, que } \\
\text { são conhecidos e publicizados. }\end{array}$} & Frequência & 4,0 & 7,0 & 3,0 & 5,0 & 2,0 \\
\hline & Percentual & 19,0 & 33,3 & 14,3 & 23,8 & 9,5 \\
\hline \multirow{2}{*}{$\begin{array}{l}\text { Q11 - A DTIC possui diretrizes claras a todos os } \\
\text { envolvidos e estão alinhadas ao PDI instituicional. }\end{array}$} & Frequência & 4,0 & 5,0 & 3,0 & 7,0 & 2,0 \\
\hline & Percentual & 19,0 & 23,8 & 14,3 & 33,3 & 9,5 \\
\hline \multirow{4}{*}{$\begin{array}{l}\text { Q12 - A DTIC possui framework adotado é voltado } \\
\text { para a estruturação dos serviços de TI com alinhamento } \\
\text { aos objetivos estratégicos do PDI - UNIPAMPA. } \\
\text { Q13 - Existe um comite e/ou conjunto de setores que } \\
\text { trata de questões importantes relacionadas à alocação } \\
\text { de recursos, à realização de investimentos e à } \\
\text { priorização de projetos de TI. }\end{array}$} & Frequência & 4,0 & 4,0 & 9,0 & 4,0 & 0,0 \\
\hline & Percentual & 19,0 & 19,0 & 42,9 & 19,0 & 0,0 \\
\hline & Frequência & 6,0 & 4,0 & 4,0 & 3,0 & 1,0 \\
\hline & Percentual & 33,3 & 22,2 & 22,2 & 16,7 & 5,6 \\
\hline \multirow{2}{*}{$\begin{array}{l}\text { Q14 - Existe um conjunto de regras que retratam o } \\
\text { modus operandi da DTIC, relacionadas, por exemplo, à } \\
\text { definição de competências, às responsabilidades de } \\
\text { cada papel contido na estrutura do setor. }\end{array}$} & Frequência & 4,0 & 4,0 & 4,0 & 4,0 & 2,0 \\
\hline & Percentual & 22,2 & 22,2 & 22,2 & 22,2 & 11,1 \\
\hline \multirow{2}{*}{$\begin{array}{l}\text { Q15 - Existe um documento formal que dispõem sobre } \\
\text { a estrutura organizacional da DTIC e o seu } \\
\text { funcionamento. }\end{array}$} & Frequência & 2,0 & 3,0 & 2,0 & 6,0 & 5,0 \\
\hline & Percentual & 11,1 & 16,7 & 11,1 & 33,3 & 27,8 \\
\hline \multirow{2}{*}{$\begin{array}{l}\text { Q16 - Existe um comitê de TI formalmente instituído e } \\
\text { que participa do planejamento estratégico. }\end{array}$} & Frequência & 3,0 & 4,0 & 6,0 & 4,0 & 1,0 \\
\hline & Percentual & 16,7 & 22,2 & 33,3 & 22,2 & 5,6 \\
\hline \multirow{2}{*}{$\begin{array}{l}\text { Q17 - Os processos são claros e descrevem um } \\
\text { conjunto organizado de práticas e atividades para } \\
\text { alcancar os objetivos. }\end{array}$} & Frequência & 4,0 & 4,0 & 5,0 & 4,0 & 1,0 \\
\hline & Percentual & 22,2 & 22,2 & 27,8 & 22,2 & 5,6 \\
\hline \multirow{2}{*}{$\begin{array}{l}\text { Q18 - Os riscos decorrentes da gestão e do uso de TI } \\
\text { que podem impactar no alcance dos objetivos são } \\
\text { monitorados. }\end{array}$} & Frequência & 0,0 & 7,0 & 4,0 & 6,0 & 1,0 \\
\hline & Percentual & 0,0 & 38,9 & 22,2 & 33,3 & 5,6 \\
\hline \multirow{2}{*}{$\begin{array}{l}\text { Q19 - Existe um planejamento a fim de atender as } \\
\text { demandas institucionais especificadas no PDI } \\
\text { institucional. }\end{array}$} & Frequência & 1,0 & 1,0 & 5,0 & 8,0 & 3,0 \\
\hline & Percentual & 5,6 & 5,6 & 27,8 & 44,4 & 16,7 \\
\hline \multirow{2}{*}{$\begin{array}{l}\text { Q20 - O corpo técnico adota as diretrizes de } \\
\text { governança de TI estabelecidas pela alta administração. }\end{array}$} & Frequência & 1,0 & 3,0 & 10,0 & 3,0 & 1,0 \\
\hline & Percentual & 5,6 & 16,7 & 55,6 & 16,7 & 5,6 \\
\hline \multirow{2}{*}{$\begin{array}{l}\text { Q21 - Pessoas influentes na instituição determinam a } \\
\text { priorização de projetos de TI com base em critérios } \\
\text { eminentemente políticos. }\end{array}$} & Frequência & 1,0 & 1,0 & 0,0 & 7,0 & 9,0 \\
\hline & Percentual & 5,6 & 5,6 & 0,0 & 38,9 & 50,0 \\
\hline \multirow{2}{*}{$\begin{array}{l}\text { Q22 - A alta administração monitora os indicadores de } \\
\text { desempenho da área de TI e toma decisões a respeito. }\end{array}$} & Frequência & 5,0 & 2,0 & 9,0 & 1,0 & 1,0 \\
\hline & Percentual & 27,8 & 11,1 & 50,0 & 5,6 & 5,6 \\
\hline \multirow{2}{*}{$\begin{array}{l}\text { Q23 - O pessoal de TI são qualificados, } \\
\text { comprometidos e adequadamente capacitados para } \\
\text { exercerem suas funções. }\end{array}$} & Frequência & 1,0 & 2,0 & 3,0 & 9,0 & 3,0 \\
\hline & Percentual & 5,6 & 11,1 & 16,7 & 50,0 & 16,7 \\
\hline
\end{tabular}
exercerem suas funções.

Fonte: Elaborado pelos autores com base nos dados da pesquisa (2017).

Cada vez mais, os gestores devem incluir o corpo técnico em TI no planejamento estratégico, na governança e na gestão organizacional (ISACA,20012). Na instituição existe 
um planejamento a fim de atender as demandas institucionais especificadas no PDI institucional, assim, entende 44,4\% dos respondentes. Contudo, 38,9\% discordam do fato que a alta administração monitora os indicadores de desempenho da área de TI e toma decisões a respeito. A alta administração possui responsabilidade direta sobre a governança de TI a fim de garantir o suporte o aprimoramento dos objetivos e o alcance das metas organizacionais (TCU-AC 2.308/2010).

Constatou-se ainda, que 55,6\% dos respondentes, mostraram-se indiferentes ao fato do corpo técnico adotar diretrizes de governança de TI estabelecidas pela alta administração. Para a maioria dos respondentes, ou seja, 38,9\% entende que os riscos no uso das tecnologias de informação e que podem impactar no alcance dos objetivos não são monitorados tão pouco possuem indicadores de desempenho.

Faz-se necessário o planejamento, desenvolvimento, execução e monitoramento das atividades em TI a fim de, atingir os objetivos corporativos. Uma gestão eficiente e eficaz de TI requer uma abordagem macro, levando-se em consideração seus diversos atores e as suas expectativas, mantendo o equilíbrio entre a execução, os benefícios e a otimização no uso dos recursos (ISACA, 2012).

\section{CONSIDERAÇÕES FINAIS}

A UNIPAMPA é uma universidade que foi criada no de 2006, devido ao projeto de interiorização do ensino aliado a política de universalização de ingresso no ensino superior. Neste tempo, a instituição, presente em dez diferentes cidades no Estado do Rio Grande do Sul, se firmou como universidade pública e de qualidade, reconhecida no Brasil e no exterior através de convênios, firmados com outras instituições de ensino.

A área da TI vem ganhando ênfase por ser considerada estratégica na condução ou mesmo no rearranjo organizacional. Desta forma, a pesquisa buscou avaliar se na UNIPAMPA as práticas voltadas à governança estratégia no âmbito da área Tecnologia da Informação e Comunicação (TIC), atinge os objetivos institucionais e estratégicos, segundo a percepção dos servidores da área. Neste prisma notou-se que, para os respondentes, a área de TI possui alinhamento com os objetivos institucionais, contudo, a governança de TI não está clara ou carece de alinhamento organizacional, bem como, falta controle e monitoria do desempenho da área de TI, pela alta administração.

A área de TI é caracterizada pela constante inovação, aliado a isso, nota-se como desafiador a promoção do planejamento estratégico organizacional com as práticas de 
governança em TI. Ressalta-se que, cabe a alta administração promover ações que visem aperfeiçoar a gestão para a continuidade do negócio, estabelecendo riscos aceitáveis, regulamentos de controle, segurança da informação bem como pessoal e equipamento necessário ao alcance dos objetivos e metas institucionais com qualidade, eficácia e efetividade dos serviços prestados (TCU-AC 1.603/2008).

A partir disso, a pesquisa apresenta como limitações a forma pela qual os dados foram analisados e coletados, não podendo os resultados serem generalizáveis. Para pesquisas futuras sugere-se ampliar esta pesquisa bem como verificar essa temática em outras realidades e com diferentes objetos de estudo.

\title{
GOVERNANCE IN THE FRAMEWORK OF THE INFORMATION TECHNOLOGY AREA: PERCEPTION OF THE SERVERS OF THE FEDERAL UNIVERSITY OF PAMPA - UNIPAMPA
}

\begin{abstract}
The objective of this study is to evaluate whether the practices focused on strategic governance in the area of Information and Communication Technology (ICT) at the Federal University of Pampa - UNIPAMPA, reach the institutional objectives proposed in the Institutional Development Plan (PDI) 2014-2018, according to the perception of the area's servers. Managers - whether in ICT or non-ICT roles - should work together to work together to ensure that ICT is included in the governance and management approach. This research is characterized as quantitative, descriptive, based on the collection of primary data, through a questionnaire, used as a data collection instrument, sent by e-mail, through a case study at the Federal University of Pampa. The main results and contributions of the study are that the IT area at the studied university has alignment with the institutional objectives, however, IT governance is not clear or lacks organizational alignment, as well as lack of control and monitoring of the performance of the area IT, by top management.

Keywords: Information Technology, Governance, Public Management, Higher Education, ICT.
\end{abstract}

\section{REFERÊNCIAS}

ALVES, L. E. S. Governança e cidadania empresarial. Revista de Administração de Empresas, São Paulo, v.41, n.4, p.78-86, out./dez. 2001.

ALVES, R. Filosofia da Ciência: Introdução ao jogo e suas regras. São Paulo: Editora Loyola, 2002.

BRASIL. Associação Brasileira de Normas Técnicas. NBR ISO/IEC 38500.

Lei 10.861 de 14 de abril de 2014. Sistema Nacional de Avaliação da Educação

Superior - SINAES. Disponível em: <http://www.planalto.gov.br/ccivil_03/_ato20042006/2004/lei/110.861.htm>. Acesso em: 20 out. 2017. 
Decreto $\mathrm{n}^{\mathrm{o}} 5.773$ de 09 de maio de 2006. Dispõe sobre o exercício das funções de regulação, supervisão e avaliação de instituições de educação superior e cursos superiores de graduação e sequenciais no sistema federal de ensino. Disponível em: <http://www.planalto.gov.br/ccivil_03/_ato2004-2006/2006/decreto/d5773.htm>. Acesso em: 11 nov. 2017.

Ministério da Educação e Cultura - MEC. Plano de Desenvolvimento Institucional PDI. Disponível em: <http://www2.mec.gov.br/sapiens/pdi.html>. Acesso em: 20 out. 2017.

Tribunal de Contas da União. Acórdão 003.732. Disponível em:<https://contas.tcu.gov.br/pesquisaJurisprudencia/\#/detalhamento/11/\%252a/NUMACOR DAO $\% 253$ A3732\%2520ANOACORDAO\%253A2014/DTRELEVANCIA\%2520desc\%252 C\%2520NUMACORDAOINT\%2520desc/false/1/false>. Acesso em: 20 out. 2017.

Tribunal de Contas da União. Acórdão 002.308. Disponível em:<http://portal.tcu.gov.br/comunidades/governanca-de-ti/entendendo-a-governanca-de-ti/>. Acesso em: 12 dez. 2017.

Tribunal de Contas da União. Acórdão 001.603. Disponível em: <https://contas.tcu.gov.br/juris/SvlHighLight?key=41434f5244414f2d434f4d504c45544f2 d3430323639\&sort=RELEVANCIA\&ordem=DESC\&bases=ACORDAO-

COMPLETO;\&highlight $=\&$ posicaoDocumento $=0 \&$ numDocumento $=1 \&$ totalDocumentos $=1>$ . Acesso em: 12 dez. 2017.

Tribunal de Contas da União. Fiscalização de Tecnologia da Informação. Disponível em: $\quad<$ http://portal.tcu.gov.br/comunidades/fiscalizacao-de-tecnologia-dainformacao/atuacao/perfil-de-governanca-de-ti/>. Acesso em: 20 out. 2017.

Tribunal de Contas da União. Governança Pública: referencial básico de governança aplicável a órgãos e entidades da administração pública e ações indutoras de melhoria. Tribunal de Contas da União. Brasília: TCU, Secretaria de Planejamento, Governança e Gestão, 2014. Disponível em: $<$ http://www.fazenda.gov.br/pmimf/institucional/download-de-arquivos/governanca-publicatcu.pdf $>$. Acesso em: 12 nov. 2017.

Tribunal de Contas da União TCU. Acórdão n. ${ }^{\circ} 003.732$ 2014. Disponível em: <http://portal.tcu.gov.br/jurisprudencia/>. Acesso em: 20 out. 2017.

Tribunal de Contas da União. Secretaria de Fiscalização de Tecnologia da Informação - Sefti. Disponível em:<http://portal.tcu.gov.br/comunidades/fiscalizacao-detecnologia-da-informacao/sefti/sobre-a-unidade/>. Acesso em: 08 nov. 2017.

Tribunal de Contas da União. Organização do Sistema de Governança de Tecnologia da Informação (TI): NOTA TÉCNICA 7/2014 SEFTI/TCU. Disponível em: <https://portal.tcu.gov.br/biblioteca-digital/organizacao-do-sistema-de-governanca-detecnologia-da-informacao-ti-nota-tecnica-7-2014-sefti-tcu-1.htm>. Acesso em: 20 out. 2017.

Universidade Federal do Pampa - UNIPAMPA. Plano de Desenvolvimento Institucional PDI.

Disponível em: 
<http://porteiras.s.unipampa.edu.br/pdi/files/2015/08/PDI_Unipampa_v19_.compressed.pdf >. Acesso em: 20 out. 2017.

. Universidade Federal do Pampa - UNIPAMPA Plano Diretor de Tecnologia da

Informação e Comunicação - PDTIC. Disponível em: <http://dtic.unipampa.edu.br/files/2016/08/PDTIC-UNIPAMPA-2017-2019.pdf>. Acesso em: 20 out. 2017.

Universidade Federal do Pampa - UNIPAMPA. Resolução no 19/2010. Disponível em: <http://porteiras.r.unipampa.edu.br/portais/consuni/files/2010/06/Res.-19_2010Regimento-NTIC.pdf.>. Acesso em: 20 out. 2017.

BRYSON, J.M.; ROERING, W. D. Apllying private-sector strategic planning in the public sector. Journal of The American Planning Association, v. 53 n. 1, 1987.

The Future of Public and Nonprofit Strategic Planning in the United States. Public Administration Review, v. 70, n. s1, p. s255-s267, 2010.

BOYNE, George A. Public and private management: what's the difference? Journal of management studies, v. 39, n. 1, p. 97-122, 2002.

CADBURY, A. 'The Corporate Governance Agenda', Corporate Governance, Vol.8, 2000.

CERNY, R. Z. Formação de Professores na Modalidade à Distância: a gestão pedagógica na perspectiva da gestão democrática. Revista do Programa de Pós-Graduação em Educaçãov. 10, n. 2, p. 87-103 2009.

CHAN, Y. E.; REICH, B. H. IT alignment: what have we learned? Journal of Information Technology (JIT). Hampshire: Palgrave Macmillan, v.22, p. 297-315, 2007.

COLOMBO, S. S. Desafios da gestão universitária contemporânea. Artmed: Porto Alegre, 2011.

DRUCKER, P. F. A Prática da administração de empresas. São Paulo: Thomson Pioneira, 1991.

FONSECA, J. J. S. Metodologia da pesquisa científica. Fortaleza: UEC, 2002.

HAIR JUNIOR, J. F.; BABIN, B.; MONEY, A. H.; SAMOUEL, P. Fundamentos de métodos de pesquisa em administração. Porto Alegre: Bookman, 2005.

HUGHES, O.E. Public Mangement and Administration. 3 ed. New York: Palgrave Macmmillan, 2003.

INSTITUTO BRASILEIRO DE GOVERNANÇA CORPORATIVA (IBGC). Código das melhores práticas de governança corporativa. 5.ed. São Paulo: IBGC, 2015. 
INTERNATIONAL FEDERATION OF ACCOUNTANTS - PSC/IFAC.Study 13.Governance in the Public Sector: A Governing Body Perspective. 2001. Disponível em: $<$ https://www.ifac.org/system/files/publications/files/study-13-governance-in-th.pdf > Acesso em: 14 de novembro de 2017.

ISACA. Information Systems Audit and Control Association. 2012. Disponível em: <http://www.isaca.org/about-isaca/Pages/default.aspx>. Acesso em: 09 dez. 2017.

JANN, W. Governance. In: EICHHORN, Peter (Org.). Verwaltungslexikon, 3. ed. Aufl. Baden, 2003.

LÖFFLER, Elke. Governance:Die neue Generation von Staats- und Verwaltungs- modernisierung.Verwaltung + Management, v. 7, n. 4, p. 212-215, 2001.

MAGAlHÃES, I. L.; PINHEIRO, W.B. Gerenciamento de Serviços de TI na Prática: Uma abordagem com base na ITIL . São Paulo: Novatec, 2007.

MALhotra, N. K. Pesquisa de Marketing: uma orientação aplicada. Porto Alegre: Bookman, 2012.

MARQUES, M. da C. da C. Aplicação dos princípios da governança corporativa ao sector público. Revista de Administração Contemporânea. Curitiba, v.11, n.2, p.11-26, abr./jun. 2007. Disponível em: <http://www.scielo.br/scielo.php?script=sci_arttext\&pid=S141565552007000200002\& lng=en\&nrm=iso>. Acesso em: 12 nov. 2017.

MATIAS-PEREIRA, J. Governança no setor público. São Paulo: Atlas, 2010.

MELO, P. A.; COLOSSI, N. (orgs). Cenários da gestão universitária na contemporaneidade. Florianópolis: Insular, 2004.

MIZAEL, G. A.; VILAS BOAS, A. A.; PEREIRA, J. R.; SANTOS, T. de S.. Análise do Plano de Desenvolvimento Institucional das universidades federais do Consórcio Sul-Sudeste de Minas Gerais. Revista de Administração Pública, v. 47, p. 1145-1164, 2013.

MORAN, José Manuel. A educação que desejamos: novos desafios e como chegar lá. $3^{a}$ edição. Editora Papirus. Campinas - SP. 2007.

MURIEL, R. Plano de desenvolvimento institucional - PDI: análise do processo de implantação. Brasil: Editora Hoper, 2006.

PFEIFFER, P. Planejamento estratégico municipal no Brasil: uma nova abordagem. Texto para discussão, v. 37 (out./2000). Brasília: ENAP, 2000.

REZENDE, D. A.. Tecnologia da Informação integrada à inteligência empresarial: Alinhamento estratégico e análise da prática nas organizações. São Paulo: Atlas, 2002.

SEGENREICH, S. C. D. O PDI como referente para avaliação de instituições de educação superior: lições de uma experiência. Ensaio, p. 149-168, 2005. 
SCHMITT, J. L.; MAFRA, W. J. O planejamento estratégico servindo para a elaboração do plano de desenvolvimento institucional. In: Encontro Nacional De Engenharia De Produção - ENEGEP, 23 e International Conference On Industrial Engeneering And Operations Management. Ouro Preto, 2003.

TRIBUNAL DE CONTAS DA UNIÃO (TCU). Governança Pública: referencial básico de governança aplicável a órgãos e entidades da administração pública e ações indutoras de melhoria. Brasília: TCU, Secretaria de Planejamento, Governança e Gestão, 2014.

VIEIRA, Rosângela Souza. O papel das tecnologias da informação e comunicação na educação: um estudo sobre a percepção do professor/aluno. RBAAD, v. 10, a. 5, p. 65-70, 2011. 